\title{
A Study of Musculoskeletal Pain among Hotel Employees, India
}

\author{
Nilesh C. Gawde \\ Assistant Professor, Centre for Public Health, School of Health Systems Studies, Tata Institute of Social Sciences, \\ Deonar - 400088, Mumbai, Maharashtra, India
}

\begin{abstract}
Background: Musculoskeletal disorders are leading cause of ill-health globally and workers are disproportionately affected due to repetitive tasks and postures. Little is known about these disorders among hotel employees in India. Objective: The study aims to find prevalence of musculoskeletal disorders among workers in luxury hotels and identify their determinants. Materials and Methods: A cross-sectional study design was employed. The study sites included eight hotels across other four cities. A pre-designed, pilot tested semi-structured questionnaire was self-administered by study respondents. Main outcome variable was self-reported musculoskeletal pain/discomfort. Data on predictor variables including socio-demographic, physical and psychosocial environment was collected. Prevalence of musculoskeletal pain/discomfort was estimated. Chi-square test was used for bi-variate analysis. Binary multiple logistic regression method was used to identify factors associated with the outcome variable 'Any chronic musculoskeletal pain' and site-specific subtypes. Results: Out of 1183 respondents, 526 (45\%) reported having musculoskeletal pain/discomfort which chiefly included backache 320 (27\%), pain in legs 206 (17\%), joint pain 157 (13\%) and neck pain 88 (7\%). 'Chronic musculoskeletal pain' was associated withfour variables; namely, years of service $(\mathrm{OR}=1.018 ; 1.002-1.034)$, heavy stress of lifting objects $(\mathrm{OR}=1.908 ; 1.289-2.825)$, psychological wellbeing (GHQ-12 item) $(\mathrm{OR}=1.214 ; 1.135-1.299)$ and type of work (desk workers had lower odds (OR $=0.355 ; 0.178-0.709$ ) than housekeepers). Conclusion: Prevalence of musculoskeletal pain/discomfort is high among hotel workers. Stress of lifting objects, psychosocial well-being, duration of service and type of work are key determinants.
\end{abstract}

Keywords: Hotel Workers, Musculoskeletal Pain, Physical Stressor, Psycho-Social Stressor

\section{Introduction}

Musculoskeletal disorders are leading cause of morbidity globally with prevalence of $8.4 \%$ and are ranked sixth in terms of disability burden ${ }^{1,2}$. Musculoskeletal disorders include injuries as well as disorders that affect the locomotive systems including chiefly the bones, joints, muscles, tendons, ligaments and nerves. While the musculoskeletal conditions could be both related to and not related to occupation of individuals, the evidence highlights that significant proportion of this burden is work-related ${ }^{3}$. A worker as part of her/his job responsibilities conducts various tasks such as bending, sitting, lifting, etc. These tasks involve biomechanical hazards which may either result in or aggravate musculoskeletal issues. Most of the empirical evidence with respect to prevalence, risk factors, and interventions comes from high income countries ${ }^{4}$. The musculoskeletal conditions have not received much attention in low income countries.

Globally, most of earlier literature on musculoskeletal conditions was concentrated on manufacturing industry ${ }^{4}$. Recently, the focus has moved to service industry as well.
There is evidence that employees in hotels and restaurants are at higher risk of musculoskeletal disorders. In the United States, musculoskeletal risk factors are highest in manufacturing sector and second highest in the hotel and catering industry ${ }^{5}$. In Denmark, age-standardised hospitalisation ratios were significantly higher among workers in hospitality compared with all working population ${ }^{6}$. The hospitality industry involves various hazards, predominantly ergonomic in nature associated with body postures, body movements and repetitive tasks.

It is important to note that hotels have various departments and tasks performed by employees varies greatly by the departments. The biomechanical risk factors vary by the jobs and hence the musculoskeletal conditions may also vary by occupations. For example, housekeeping is associated lifting weights and thus with low back pain and desk-work with neck pain ${ }^{4,7,8}$. Lee et al. (2013) notes that research on work-related musculoskeletal disorders among hotel workers has targeted only kitchen and housekeeping departments and not investigated the entire range of hotel workers ${ }^{5}$.

\footnotetext{
${ }^{*}$ Author for correspondence
} 
There is dearth of literature on prevalence of musculoskeletal conditions among hotel workers in India. In fact, there are only a few research papers on health of hotel workers or on musculoskeletal disorders ${ }^{9-11}$. This study was therefore undertaken to find prevalence of symptoms related to musculoskeletal conditions among hotel workers and to identify risk factors associated with the musculoskeletal conditions.

\section{Subjects and Methods}

This paper is part of a larger study of morbidity, mental wellbeing and risk factors among hotel employees. This section covers methods relevant to musculoskeletal conditions. Since, the study objective was to find out prevalence of musculoskeletal conditions, cross-sectional study design was adopted. We listed key variables within the domains of psychosocial well-being, physical stress, work hours, etc. based upon a musculoskeletal health model ${ }^{12}$ and looked for their association with presence or absence of musculoskeletal conditions.

\subsection{Study Variables and Tools}

Socio-demographic variables included age, sex, education, marital status, income and type of house. Data on years in service, type of occupation (housekeeping, food preparation, etc.), stress of lifting objects at workplace and average number of extra-hours of work per week was collected for assessing physical working conditions. Psychosocial well-being were measured by 12 -item General Health Questionnaire (GHQ-12) ${ }^{13}$. Body mass index was also included. For these musculoskeletal conditions, self-reported data on musculoskeletal pain was collected. With respect to musculoskeletal pain, variables included 'site of musculoskeletal pain', 'duration of pain' (less than or more than 15 days), 'whether pain reported to supervisor,', and 'reasons for not reporting to supervisor. Clinical examination or confirmation was not part of the study protocol. A pre-designed self-administered tool was prepared in English by two researchers and modified with comments from academicians and practitioners. A draft tool was prepared in discussion with faculty from occupational health sciences as well as the human resource managers in the hotels. The draft tool was pilot tested with 14 employees in one of the hotels; these 14 did not participate in the final survey. With respect to musculoskeletal conditions, pilot highlighted need to collect pain data site wise and that on hospitalization and chronic conditions due to musculoskeletal conditions. Relevant questions were added to the questionnaire based on the results of pilot test.

\subsection{Study Settings and Sampling}

The data or this study has been collected from luxury hotels. A chain of hotels had three luxury hotels in Mumbai and all employees from these three hotels (approximately 2500) were invited to participate. In order to reflect situation from other hotels in the chain, two luxury hotels from Delhi, one luxury hotel from Kochi and one semi-luxury hotel from Delhi and Nasik were also included. However for these, only a total of 300 employees were randomly selected given feasibility constraints. Data from all these hotels has been analysed together.

\subsection{Data Analysis}

Data was collected by self-administered questionnaires in Hindi and English. Research staff checked all the questionnaires manually first and then entered data in IBM spss version 16. The questions had option 'Don't know', 'Can't say' and if the respondent did not want to respond she/he could keep the field blank. Data was cleaned and analysed with frequency and percentages. Occupation was coded into one of the seven categories; namely housekeeping, desk workers, food preparation, food service, engineering and security (as single category), front office and others. Stress of lifting objects depends upon number of times object/s is/are lifted and weight of the objects. For the purpose of this study, we operationally defined stress as low, moderate or heavy based upon these two criteria (Figure 1). Body Mass Index was categorised into four categories; less than 18.5 as underweight, 18.5 to 24.9 normal, 25 to 29.9 as overweight and more than 30 as obese. ${ }^{14} \mathrm{Bi}$-variate analysis was conducted for musculoskeletal pain at any site and then specifically for back, neck, leg and joints. Multivariate analysis (multiple binary logistic regressions) was performed for musculoskeletal pain (any) and subgroups (site-specific musculoskeletal pain such as pain in back, neck, leg and joints) to find adjusted odds ratios. While performing multivariate analysis; GHQ score, years of service and hours of overtime per week were taken as continuous variables whereas others continued to be categorical. Age was not included in bi or multi-variate analyses as it had high collinearity with years of service.

\begin{tabular}{|l|c|c|c|c|c|}
\hline $\begin{array}{c}\text { Number of times } \\
\text { object/s is/are } \\
\text { lifted every day }\end{array}$ & $\begin{array}{c}\mathbf{0 - 5} \\
\mathbf{K g}\end{array}$ & $\begin{array}{c}\mathbf{5 - 1 0} \\
\mathbf{K g}\end{array}$ & $\mathbf{1 1 - 2 0 ~ \mathbf { ~ g }}$ & $\begin{array}{c}\mathbf{2 1 - 3 0} \\
\mathbf{K g}\end{array}$ & $\begin{array}{c}\mathbf{3 0} \\
\mathbf{K g}\end{array}$ \\
\hline One or two times & $\mathrm{L}$ & $\mathrm{L}$ & $\mathrm{L}$ & $\mathrm{M}$ & $\mathrm{H}$ \\
\hline $\begin{array}{l}\text { Three to five } \\
\text { times }\end{array}$ & $\mathrm{L}$ & $\mathrm{L}$ & $\mathrm{M}$ & $\mathrm{H}$ & $\mathrm{H}$ \\
\hline Six to ten times & $\mathrm{L}$ & $\mathrm{M}$ & $\mathrm{M}$ & $\mathrm{H}$ & $\mathrm{H}$ \\
\hline $\begin{array}{l}\text { More than ten } \\
\text { times }\end{array}$ & $\mathrm{M}$ & $\mathrm{H}$ & $\mathrm{H}$ & $\mathrm{H}$ & $\mathrm{H}$ \\
\hline
\end{tabular}

L: Light stress, M: Moderate stress, H: Heavy stress

Figure 1. Classification of Stress of lifting objects. 


\subsection{Ethical Considerations}

The study followed ethical principles of Declaration of Helsinki. Being of observational nature, the study did not involve major ethical concerns. Permission to conduct was sought from all hotels. A written informed consent was obtained before participation from the respondents. The rights to privacy and confidentiality were explained to the eligible respondents.

\section{Results}

Out of estimated eligible respondents (2800) in sampling frame, 1183 (42.3\%) participated in the study. Out of the 1183 hotel employees, 526 (44.5\%) reported chronic musculoskeletal pain for at least two weeks during past six months (Table 1). Pain in the back was most common $(320 ; 27.0 \%)$ followed by that in legs (206; 17.4\%), joints $(157 ; 13.3 \%)$ and neck $(88 ; 7.4 \%)$. More than half $(297$ out of $519 ; 57.2 \%$ ) of the workers who had chronic musculoskeletal pain had not reported same to their supervisors or physicians. Most common reasons of not reporting were that 'the workers thought that it would get better on its own' $(204 ; 68.7 \%)$ and that 'they did not know that they should report to supervisor' $(81 ; 27.3 \%)$. Other common reasons included 'Supervisor is not empathetic to him/her and reporting won't be useful' (52, 17.5\%), 'too many steps in reporting' $(49 ; 16.5 \%)$, 'Fear that career will get affected although job will be retained' $(34 ; 11.4 \%)$, etc.

Table 2 shows that among various departments within hotel, housekeeping and restaurant had higher prevalence of any chronic pain and most of the site-specific musculoskeletal pains. Males were significantly more likely to have musculoskeletal pain than females. Proportion of individuals with pain increased as the years of service and stress of lifting objects increased. Mental wellbeing was negatively associated with having chronic musculoskeletal pain or having any site-specific pain. Among specific musculoskeletal pain subgroups, back pain was associated with occupational group and stress of lifting objects. Pain in neck was associated with lifting heavy objects. Pain in legs was associated with years of service. Pain in joints was associated with both lifting heavy objects and with years of service. Body mass index and doing overtime were not found to be associated with any of the pain.

Table 1. Chronic musculoskeletal pain among hotel workers and their access to healthcare.

\begin{tabular}{|c|c|}
\hline & Number (\%) \\
\hline \multicolumn{2}{|l|}{ Chronic musculoskeletal pain $(n=1183)$} \\
\hline Any chronic musculoskeletal pain & $526(44.5)$ \\
\hline \multicolumn{2}{|l|}{ Site-wise musculoskeletal pain } \\
\hline Back & $320(27.0)$ \\
\hline Neck & $88(7.4)$ \\
\hline Joint & $157(13.3)$ \\
\hline Leg & $206(17.4)$ \\
\hline \multicolumn{2}{|l|}{ Reporting musculoskeletal pain to supervisor $(n=519)^{\star}$} \\
\hline Reported pain to supervisor & $222(42.8)$ \\
\hline Did not report pain to supervisor & $297(57.2)$ \\
\hline \multicolumn{2}{|l|}{ Reasons for not reporting pain to supervisor or physician $(n=297)$} \\
\hline Thought that it would get better & $204(68.7)$ \\
\hline Did not know that he/she should report to supervisor & $81(27.3)$ \\
\hline Supervisor is not empathetic to him/her and reporting won't be useful & $52(17.5)$ \\
\hline Too many steps in reporting & $49(16.5)$ \\
\hline Fear that career will get affected although job will be retained & $34(11.4)$ \\
\hline Fear of getting into trouble if pain is reported\# & $28(9.4)$ \\
\hline She/he did not want to take a test or medicines & $26(8.8)$ \\
\hline Fear of loosing the job & $16(5.4)$ \\
\hline Co-worker told her/him not to tell supervisor & $9(3.0)$ \\
\hline Other reasons & $12(4.0)$ \\
\hline
\end{tabular}

* Seven respondents did not respond to question about reporting pain to supervisor

\# This is exclusive of fear of loosing job or career advancement within the hotel 
Table 2. Musculoskeletal pain among hotel workers according to socio-demographic characteristics and working conditions\#.

\begin{tabular}{|c|c|c|c|c|c|}
\hline \multirow{2}{*}{$\begin{array}{l}\text { Socio-demographic } \\
\text { characteristics and } \\
\text { working conditions }\end{array}$} & \multirow{2}{*}{$\begin{array}{l}\text { Any chronic } \\
\text { musculoskeletal pain }\end{array}$} & \multicolumn{4}{|c|}{ Musculoskeletal Pain at specific sites } \\
\hline & & Back & Neck & Leg & Joints \\
\hline Sex & $\left(\chi^{2}=7.079\right)^{\star}$ & $\left(\chi^{2}=2.765\right)$ & $\left(\chi^{2}=2.347\right)$ & $\left(\chi^{2}=3.242\right)$ & $\left(\chi^{2}=0.490\right)$ \\
\hline Male & $477(45.9)$ & $290(27.9)$ & $73(7.0)$ & $189(18.2)$ & $140(13.5)$ \\
\hline Female & $48(34.0)$ & $30(21.3)$ & $15(10.6)$ & $17(12.1)$ & $16(11.3)$ \\
\hline BMI & $\left(\chi^{2}=2.548\right)$ & $\left(\chi^{2}=2.058\right)$ & $\left(\chi^{2}=0.575\right)$ & $\left(\chi^{2}=3.761\right)$ & $\left(\chi^{2}=4.317\right)$ \\
\hline Underweight & $30(50.8)$ & $21(35.6)$ & $4(6.8)$ & $7(11.9)$ & $6(10.2)$ \\
\hline Normal & $221(42.7)$ & $139(26.9)$ & $39(7.5)$ & $83(16.1)$ & $61(11.8)$ \\
\hline Overweight & $150(46.0)$ & $93(28.5)$ & $26(8.0)$ & $66(20.2)$ & $51(15.6)$ \\
\hline Obese & $51(48.6)$ & $29(27.6)$ & $10(9.5)$ & $18(17.1)$ & $18(17.1)$ \\
\hline Years of service & $\left(\chi^{2}=22.798\right)^{*}$ & $\left(\chi^{2}=3.881\right)$ & $\left(\chi^{2}=6.309\right)$ & $\left(\chi^{2}=19.830\right)^{*}$ & $\left(\chi^{2}=30.917\right)^{\star}$ \\
\hline$<5$ years & $138(37.6)$ & $91(24.8)$ & $21(5.7)$ & $48(13.1)$ & $32(8.7)$ \\
\hline 5 to $<10$ years & $85(39.7)$ & $56(26.2)$ & $14(6.5)$ & $31(14.5)$ & $17(7.9)$ \\
\hline 10 to $<20$ years & $136(48.7)$ & $79(28.3)$ & $23(8.2)$ & $50(17.9)$ & $43(15.4)$ \\
\hline 20 to $<30$ years & $43(46.2)$ & $24(25.8)$ & $6(6.5)$ & $17(18.3)$ & $17(18.3)$ \\
\hline 30 or more years & $116(56.3)$ & $66(32.0)$ & $23(11.2)$ & $56(27.2)$ & $47(22.8)$ \\
\hline $\begin{array}{l}\text { Stress of lifting weights } \\
\text { at workplace }\end{array}$ & $\left(\chi^{2}=42.969\right)^{*}$ & $\begin{array}{c}\left(\chi^{2}=\right. \\
36.246)^{\star}\end{array}$ & $\left(\chi^{2}=7.905\right)^{\star}$ & $\left(\chi^{2}=11.545\right)$ & $\left(\chi^{2}=30.849\right)^{*}$ \\
\hline Low & $140(32.8)$ & $72(16.9)$ & $21(4.9)$ & $54(12.6)$ & $28(6.6)$ \\
\hline Moderate & $54(45.4)$ & $41(34.5)$ & $13(10.9)$ & $23(19.3)$ & $15(12.6)$ \\
\hline Heavy & $169(57.3)$ & $104(35.3)$ & $28(9.5)$ & $65(22.0)$ & $60(20.3)$ \\
\hline Occupational group & $\left(\chi^{2}=26.503\right)^{*}$ & $\begin{array}{c}\left(\chi^{2}=\right. \\
20.753)^{\star}\end{array}$ & $\left(\chi^{2}=5.435\right)$ & $\left(\chi^{2}=11.190\right)$ & $\left(\chi^{2}=14.025\right)^{*}$ \\
\hline Housekeeping & $107(52.5)$ & $67(32.8)$ & $17(8.3)$ & $42(20.6)$ & $37(18.1)$ \\
\hline Desk workers & $38(31.1)$ & $19(15.6)$ & $12(9.8)$ & $14(11.5)$ & $9(7.4)$ \\
\hline Front office & $28(44.4)$ & $17(27.0)$ & $5(7.9)$ & $6(9.5)$ & $6(9.5)$ \\
\hline Restaurant & $167(48.1)$ & $109(31.4)$ & $30(8.6)$ & $69(19.9)$ & $51(14.7)$ \\
\hline Kitchen and bakery & $146(46.1)$ & $85(26.8)$ & $19(6.0)$ & $59(18.6)$ & $45(14.2)$ \\
\hline Others & $17(27.0)$ & $10(15.9)$ & $2(3.2)$ & $8(12.7)$ & $5(7.9)$ \\
\hline Security and engineering & $23(34.8)$ & $13(19.7)$ & $3(4.5)$ & $8(12.1)$ & $4(6.1)$ \\
\hline $\begin{array}{l}\text { Psychological wellbeing } \\
\text { (General Health } \\
\text { Questionnaire - } 12 \\
\text { score) }\end{array}$ & $\left(\chi^{2}=40.022\right)^{*}$ & $\begin{array}{c}\left(\chi^{2}=\right. \\
33.926)^{*}\end{array}$ & $\left(\chi^{2}=10.702\right)^{\star}$ & $\left(\chi^{2}=16.816\right)^{*}$ & $(\chi 2=6.117)^{*}$ \\
\hline $0-2$ & $249(36.7)$ & $140(20.6)$ & $36(5.3)$ & $92(13.5)$ & $76(11.2)$ \\
\hline $3-12$ & $277(55.2)$ & $180(35.9)$ & $52(10.4)$ & $114(22.7)$ & $81(16.1)$ \\
\hline Overtime & $\left(\chi^{2}=0.974\right)$ & $\left(\chi^{2}=0.014\right)$ & $\left(\chi^{2}=0.581\right)$ & $\left(\chi^{2}=0.951\right)$ & $\left(\chi^{2}=1.100\right)$ \\
\hline At least once a week & $133(41.8)$ & $86(27.0)$ & $27(8.5)$ & $51(16.0)$ & $36(11.3)$ \\
\hline Rarely & $353(45.1)$ & $209(26.7)$ & $56(7.2)$ & $145(18.5)$ & $107(13.7)$ \\
\hline
\end{tabular}

\# The data was collected by a self-administered tool and some respondents had left certain fields blank. Hence, the total may not add up to 526 . 
Table 3. Multi-variate regression analysis of musculoskeletal pain by socio-demographic characteristics and working conditions $(\mathrm{n}=543) \#$.

\begin{tabular}{|c|c|c|c|c|c|}
\hline \multirow{2}{*}{$\begin{array}{l}\text { Socio-demographic } \\
\text { characteristics and } \\
\text { working conditions }\end{array}$} & \multirow{2}{*}{$\begin{array}{c}\text { Any chronic } \\
\text { musculoskeletal pain }\end{array}$} & \multicolumn{4}{|c|}{ Musculoskeletal Pain at specific sites } \\
\hline & & Back & Neck & Leg & Joints \\
\hline \multicolumn{6}{|l|}{ Sex } \\
\hline Male & Reference & Reference & Reference & Reference & Reference \\
\hline Female & $\begin{array}{c}0.684 \\
(0.368-1.270) \\
\end{array}$ & $\begin{array}{c}0.911 \\
(0.452-1.836) \\
\end{array}$ & $\begin{array}{c}2.556 \\
(0.935-6.986) \\
\end{array}$ & $\begin{array}{c}0.836 \\
(0.366-1.905) \\
\end{array}$ & $\begin{array}{c}1.318 \\
(0.484-3.589) \\
\end{array}$ \\
\hline \multicolumn{6}{|l|}{ BMI } \\
\hline Normal & Reference & Reference & Reference & Reference & Reference \\
\hline Underweight & $\begin{array}{c}1.487 \\
(0.703-3.147) \\
\end{array}$ & $\begin{array}{c}1.615 \\
(0.752-3.470)\end{array}$ & $\begin{array}{c}0.572 \\
(0.124-2.638)\end{array}$ & $\begin{array}{c}1.017 \\
(0.388-2.666)\end{array}$ & $\begin{array}{c}1.037 \\
(0.329-3.267) \\
\end{array}$ \\
\hline Overweight & $\begin{array}{c}1.186 \\
(0.816-1.725) \\
\end{array}$ & $\begin{array}{c}1.233 \\
(0.816-1.864) \\
\end{array}$ & $\begin{array}{c}1.231 \\
(0.631-2.400) \\
\end{array}$ & $\begin{array}{c}1.206 \\
(0.756-1.923) \\
\end{array}$ & $\begin{array}{c}1.392 \\
(0.814-2.378) \\
\end{array}$ \\
\hline Obese & $\begin{array}{c}1.344 \\
(0.771-2.343) \\
\end{array}$ & $\begin{array}{c}1.109 \\
(0.600-2.049) \\
\end{array}$ & $\begin{array}{c}1.501 \\
(0.597-3.777) \\
\end{array}$ & $\begin{array}{c}0.940 \\
(0.455-1.943) \\
\end{array}$ & $\begin{array}{c}1.377 \\
(0.638-2.973) \\
\end{array}$ \\
\hline Years of service & $\begin{array}{c}1.018^{\star} \\
(1.002-1.034) \\
\end{array}$ & $\begin{array}{c}1.001 \\
(0.984-1.018) \\
\end{array}$ & $\begin{array}{c}1.022 \\
(0.995-1.049) \\
\end{array}$ & $\begin{array}{c}1.025^{\star} \\
(1.005-1.044) \\
\end{array}$ & $\begin{array}{c}1.034^{\star} \\
(1.012-1.056) \\
\end{array}$ \\
\hline \multicolumn{6}{|l|}{$\begin{array}{c}\text { Stress of lifting } \\
\text { objects at workplace }\end{array}$} \\
\hline Low & Reference & Reference & Reference & Reference & Reference \\
\hline Moderate & $\begin{array}{c}1.424 \\
(0.853-2.378) \\
\end{array}$ & $\begin{array}{c}2.178^{\star} \\
(1.289-3.680) \\
\end{array}$ & $\begin{array}{c}3.622^{\star} \\
(1.458-9.001) \\
\end{array}$ & $\begin{array}{c}1.266 \\
(0.671-2.389) \\
\end{array}$ & $\begin{array}{c}1.925 \\
(0.880-4.211) \\
\end{array}$ \\
\hline Heavy & $\begin{array}{c}1.908^{\star} \\
(1.289-2.825) \\
\end{array}$ & $\begin{array}{c}2.505^{\star} \\
(1.649-3.806) \\
\end{array}$ & $\begin{array}{c}2.515^{\star} \\
(1.132-5.586) \\
\end{array}$ & $\begin{array}{c}1.065 \\
(0.645-1.758) \\
\end{array}$ & $\begin{array}{c}2.902^{\star} \\
(1.577-5.341) \\
\end{array}$ \\
\hline \multicolumn{6}{|l|}{ Occupational group } \\
\hline Housekeeping & Reference & Reference & Reference & Reference & Reference \\
\hline Desk workers & $\begin{array}{c}0.355^{\star} \\
(0.178-0.709) \\
\end{array}$ & $\begin{array}{c}0.549 \\
(0.248-1.215) \\
\end{array}$ & $\begin{array}{c}0.741 \\
(0.202-2.711) \\
\end{array}$ & $\begin{array}{c}0.466 \\
(0.194-1.119) \\
\end{array}$ & $\begin{array}{c}0.732 \\
(0.258-2.077) \\
\end{array}$ \\
\hline Front office & $\begin{array}{c}1.214 \\
(0.530-2.780) \\
\end{array}$ & $\begin{array}{c}1.077 \\
(0.437-2.652) \\
\end{array}$ & $\begin{array}{c}1.877 \\
(0.538-6.557) \\
\end{array}$ & $\begin{array}{c}0.358 \\
(0.097-1.322) \\
\end{array}$ & $\begin{array}{c}0.918 \\
(0.268-3.145) \\
\end{array}$ \\
\hline Restaurant & $\begin{array}{c}0.817 \\
(0.486-1.375) \\
\end{array}$ & $\begin{array}{c}1.031 \\
(0.583-1.822) \\
\end{array}$ & $\begin{array}{c}1.112 \\
(0.445-2.778) \\
\end{array}$ & $\begin{array}{c}0.702 \\
(0.373-1.323) \\
\end{array}$ & $\begin{array}{c}0.928 \\
(0.450-1.914) \\
\end{array}$ \\
\hline Kitchen and bakery & $\begin{array}{c}0.870 \\
(0.519-1.457) \\
\end{array}$ & $\begin{array}{c}0.924 \\
(0.528-1.619) \\
\end{array}$ & $\begin{array}{c}0.948 \\
(0.376-2.393) \\
\end{array}$ & $\begin{array}{c}0.877 \\
(0.472-1.630) \\
\end{array}$ & $\begin{array}{c}1.160 \\
(0.578-2.328) \\
\end{array}$ \\
\hline Others & $\begin{array}{c}0.588 \\
(0.258-1.338) \\
\end{array}$ & $\begin{array}{c}0.688 \\
(0.269-1.758) \\
\end{array}$ & $\begin{array}{c}0.564 \\
(0.109-2.920) \\
\end{array}$ & $\begin{array}{c}0.729 \\
(0.262-2.030) \\
\end{array}$ & $\begin{array}{c}0.857 \\
(0.257-2.857) \\
\end{array}$ \\
\hline $\begin{array}{l}\text { Security and } \\
\text { Engineering } \\
\end{array}$ & $\begin{array}{c}0.663 \\
(0.300-1.466) \\
\end{array}$ & $\begin{array}{c}0.966 \\
(0.387-2.407) \\
\end{array}$ & $\begin{array}{c}0.426 \\
(0.050-3.617) \\
\end{array}$ & $\begin{array}{c}0.635 \\
(0.218-1.850) \\
\end{array}$ & $\begin{array}{c}0.371 \\
(0.078-1.767) \\
\end{array}$ \\
\hline $\begin{array}{c}\text { Psychological } \\
\text { Wellbeing (General } \\
\text { Health Questionnaire } \\
-12 \text { - score) }\end{array}$ & $\begin{array}{c}1.214^{\star} \\
(1.135-1.299)\end{array}$ & $\begin{array}{c}1.161^{\star} \\
(1.082-1.247)\end{array}$ & $\begin{array}{c}1.146^{\star} \\
(1.026-1.281)\end{array}$ & $\begin{array}{c}1.142^{\star} \\
(1.054-1.237)\end{array}$ & $\begin{array}{c}1.060 \\
(0.964-1.166)\end{array}$ \\
\hline Hours of overtime & $\begin{array}{c}1.010 \\
(0.991-1.029) \\
\end{array}$ & $\begin{array}{c}1.022^{\star} \\
(1.002-1.043) \\
\end{array}$ & $\begin{array}{c}1.015 \\
(0.983-1.048) \\
\end{array}$ & $\begin{array}{c}1.008 \\
(0.985-1.033) \\
\end{array}$ & $\begin{array}{c}0.987 \\
(0.956-1.018) \\
\end{array}$ \\
\hline Constant & 0.287 & 0.105 & 0.015 & 0.110 & 0.042 \\
\hline
\end{tabular}

\# Only 543 respondents had completed the entire questionnaire; hence multiple regression analysis was limited to this number. 
Multivariate analyses (Table 3) showed that with increasing years of service, chances of any chronic pain, pain in legs and joints increased. Adjusted odds of having all types of pain (except neck pain) were significantly higher among those who had heavy load of lifting objects. After adjusting for other variables, occupational group was not found to be significantly associated with any site-specific pain. However, housekeeping still had higher odds than desk workers when all types of pain were combined (any chronic pain). Lack of mental well-being had consistently and significantly higher odds of all types of pain.

\section{Discussion}

This is first Indian study which documents prevalence of musculoskeletal conditions among hotel employees. The prevalence is undoubtedly high affecting nearly half of the employees. The findings are important because most of previous research was among specific occupational types such as housekeeping or restaurant ${ }^{5,15}$. The prevalence was highest among the housekeeping staff followed by restaurant and kitchen and bakery staff. The prevalence was higher among men, those with more number of service years, heavy physical work involving lifting of objects and poor psychosocial well-being. A previous study from South Korea also showed that heavy physical work was associated with higher prevalence of musculoskeletal disorders; however, that study found prevalence to be higher among men ${ }^{5}$. Differences across gender could be because there is division of labor based on gender in India which results in differential exposures of the two genders to the ergonomic and psychosocial risk factors 5 . After adjusting for the stress of lifting objects and psychosocial well-being, there was no gender-wise difference indicating that the difference may be due to such physical or psychosocial factors.

As seen in this study, more than half did not report pain to supervisor or physician. This is similar to the findings from high income countries ${ }^{16}$. Most common reasons in literature, 'I thought it would get better' and 'I did not know I should' were found in this study as well. Other reasons that were found to contribute to poor access to health care include 'too many steps in reporting, 'fear of getting in trouble, 'fear of losing job' and 'supervisor did not understand me'. It is important to sensitise the workers about importance and benefits of early reporting.

Recent literature has attempted to identify the specific biomechanical factors that lead to musculoskeletal conditions. A recent meta-analysis which pooled data from various studies found that biomechanical risk factors with at least reasonable evidence include excessive repetition, awkward postures, and heavy lifting ${ }^{4}$. In the present study also, heavy lifting was found to be associated with musculoskeletal pain; however, we did not assess specific biomechanical factors such as bending, carrying, awkward postures, etc. Similar to previous studies ${ }^{6,17}$, the association between stress of lifting weight and musculoskeletal pain persisted to be significant even after controlling for other variables. ${ }^{16}$ Literature also documents role of years of service, housekeeping job and psychosocial well-being in causing musculoskeletal disorders as reported in this study. ${ }^{4}$ For each anatomical sites of pain, there are some specific ergonomic factors that play a role. Therefore, we discuss site specific pains in detail in next paragraphs.

In this study, back pain was most commonly reported site of pain which is consistent with existing literature ${ }^{7,18}$. Among all hotel workers, housekeeping staff had higher prevalence of backache and this again is consistent with existing literature ${ }^{18}$. However, after adjusting for heavy workload and other factors, odds of musculoskeletal pain among various occupational groups within the hotel were not significantly different in this study. A systematic review documented association of backache with lifting heavy weights ${ }^{19}$ and this study shows similar finding. Prevalence of low back pain was high (one fourth) even among those with less than five years of service. The increase in prevalence thereafter was not significant which has also been documented in past ${ }^{20,21}$. The point of concern here is that the back pain sets in early among sizeable number of workers and needs priority attention.

The risk factors associated with neck pain are much different from that of back pain. Female gender has been documented risk factor for neck pain ${ }^{4}$; this study's findings also show high (although not significantly higher) neck pain prevalence among women workers. There is insufficient evidence of heavy physical work or lifting causing neck pain. However, in the present study, the stress due to lifting objects was found to be associated with neck pain. This may be because lifting of objects within hotel settings often involve arm or hand movements which affect the neck/shoulder musculature and generate loads on the neck/shoulder area. Daily sitting time has strong correlation with pain in neck is daily sitting time $e^{8}$. Although in this study, we did not measure the sitting time, prevalence of neck pain was highest among the desk workers.

This study included all joint pains as single category. The anatomical position and physiological function of joints vary and a particular physical stress may affect one joint but not the other. It is possible that specific joints have specific stressors but the absolute number of specific joint pains were smaller which prevented advanced statistical analysis of the joint sub-groups (knee, shoulder, etc.). In the present study, we found that lifting heavy weight was associated with joint pain. There is some evidence regarding this with respect to knee joint ${ }^{4}$. Lifting heavy objects may also affect the joints of upper extremity especially the shoulder joint.

With respect to pain in legs, previous studies have not identified specific biomechanical risk factor ${ }^{4}$. Standing time is associated with pain in legs'; however, we did not measure 
standing time in this study which may be associated with pain in leg. Among the factors studied, only years of service and mental well-being were associated with having pain in legs.

Psychological well-being was found to be associated with most types of chronic musculoskeletal pain in this study. Psycho-social factors have been incriminated in musculoskeletal conditions in past ${ }^{22,23}$. Being a cross-sectional study, it is difficult to determine temporality and thereby causality. It is also possible that the scores on GHQ-12 were higher due to musculoskeletal pain affecting psychological well-being.

It is important to look for possible means of reducing musculoskeletal pain. The interventions can include change in physical structures which could reduce the instances of lifting weights ${ }^{24}$. Design of equipment such as trolleys will determine the push-pull force needed to move them and appropriate design can reduce forces and avoid lifting of heavy objects. In addition to these, ergonomic training has been found to be useful ${ }^{18}$.

The study had certain limitations. Self-reported musculoskeletal pain was the chief outcome measure which has a possibility of underestimation. With respect to physical work, stress due to lifting objects was assessed. However, static loads such as prolonged standing, sitting, carrying/holding objects was not measured. Detailed ergonomic study is required to understand various physical stressors that are peculiar to each department. Similarly psychosocial factors were studied by GHQ but specific psychosocial factors such as job control, job demand, and social support were not studied. Nevertheless, the study highlights neglected burden of musculoskeletal conditions and physical and psychosocial factors responsible for same.

\section{Conclusion}

The hotel workers have high burden of musculoskeletal conditions. The musculoskeletal pain is associated with physical stress of lifting objects and mental well-being after adjusting for other variables indicating that these conditions are related to work stressors. In order to improve health of the hotel workers, intervention studies are needed where ergonomic as well as psychosocial factors are addressed in a holistic manner.

\section{References}

1. Smith E, Hoy DG, Cross M, Vos T, Naghavi M, Buchbinder R, et al. The global burden of other musculoskeletal disorders: estimates from the Global Burden of Disease 2010 study. Annals of the Rheumatic Diseases. 2014; 73(8):1462-9. https://doi. org/10.1136/annrheumdis-2013-204680 https://doi.org/10.1136/ annrheumdis-2013-204647
2. Palazzao C, Ravaud JF, Papelard A, Ravaud P, Poiraudeau S. The burden of musculoskeletal conditions. Plos ONE. 2014; 9(3):e90633. https://doi.org/10.1371/journal.pone.0090633 PMid:24595187 PMCid:PMC3942474.

3. Mustard CA, Chambers A, Ibrahim S, Etches J, Smith P. Time trends in musculoskeletal disorders attributed to work exposures in Ontario using three independent data sources, 2004-2011. Occupational and Environmental Medicine. 2015; 72(4):252-7. https://doi.org/10.1136/oemed-2014-102442

4. da Costa BR, Vieira ER. Risk factors for work-related musculoskeletal disorders: a systematic review of recent longitudinal studies. American Journal of Industrial Medicine. 2010; 53(3):285-323. PMid:19753591.

5. Lee JW, Lee JJ, MUN HJ, Lee KJ, Kim JJ. The relationship between musculoskeletal symptoms and work-related risk factors in hotel workers. Annals of Occupational and Environmental Medicine. 2013; 25(1):20. https://doi.org/10.1186/2052-4374-25-20

6. Hannerz H, Tuchsen F, Kristensen TS. Hospitalizations among employees in the Danish hotel and restaurant industry. European Journal of Public Health. 2002; 12(3):192-7. https://doi. org/10.1093/eurpub/12.3.192 PMid:12232958.

7. Krause N, Scherzer T, Rugulies R. Physical workload, work intensification, and prevalence of pain in low wage workers: results from a participatory research project with hotel room cleaners in Las Vegas. American Journal of Industrial Medicine. 2005; 48(5):326-37. https://doi.org/10.1002/ajim.20221 PMid:16193494.

8. Hallman DM, Gupta N, Mathiassen SE, Holtermann A. Association between objectively measured sitting time and neckshoulder pain among bluecollar workers. International Archives of Occupational and Environmental Health. 2015; 88(8):103142. https://doi.org/10.1007/s00420-015-1031-4.

9. Gangopadhyay S, Dev S, Das T, Ghoshal G, Ara T. An ergonomics study on the prevalence of musculoskeletal disorders among Indian bus conductors. International Journal of Occupational Safety and Ergonomics. 2012; 18(4):521-30. https://doi.org/10.1 080/10803548.2012.11076957 PMid:23294656.

10. Subramaniam S, Murugesan S. Investigation of work-related musculoskeletal disorders among male kitchen workers in South India. International Journal of Occupational Safety and Ergonomics. 2015; 21(4):524-31. https://doi.org/10.1080/10803548.2015.1096063

11. Gawde NC, Kurlikar PR. Chronic disease risk factors among hotel workers. Indian Journal of Occupational and Environmental Medicine. 2016; 20(1):14-20. https://doi.org/10.4103/00195278.18380

12. Punnett L, Cherniack M, Henning R, Morse T, Faghri P, CPHNEW Research Team. A conceptual framework for integrating workplace health promotion and occupational ergonomics programs. Public Health Reports. 2009; 124(Suppl 1):16-25. https://doi.org/10.1177/00333549091244S103 PMid:19618803 PMCid:PMC2708653.

13. Golderberg D, Williams P. A user's guide to the General Health Questionnaire. Windsor, UK: NFER-Nelson; 1988. 
14. WHO. Obesity: preventing and managing the global epidemic. Report of a WHO Consultation. WHO Technical Report Series 894. Geneva: World Health Organization. 2000.

15. Chyuan JYA, Du CL, Yeh WY, Li CY. Musculoskeletal disorders in hotel restaurant workers. Occupational Medicine (London). 2004; 54(1):55-7. https://doi.org/10.1093/occmed/kqg108

16. Scherzer T, Rugulies R, Krause N. Work-related pain and injury and barriers to workers' compensation among Las Vegas hotel room cleaners. American Journal of Public Health. 2005; 95(3):483-8. https://doi.org/10.2105/AJPH.2003.033266.

17. Lahelma E, Laaksonen M, Lallukka T, Martikainen P, Pietilainen $\mathrm{O}$, Saastamoinen $\mathrm{P}$, et al. Working conditions as risk factors for disability retirement: a longitudinal register linkage study. BMC Public Health. 2012; 12:309. https://doi.org/10.1186/1471-245812-309 PMid:22537302 PMCid:PMC3438015.

18. Salwe K, Kumar S, Hood J. Nonfatal occupational injury rates and musculoskeletal symptoms among housekeeping employees of a hospital in Texas. Journal of Environmental and Public Health. 2011; 2011:382510. Epub 2011 Jun 5. https://doi. org/10.1155/2011/382510

19. Griffith LE, Shannon HS, Wells RP, Walter SD, Cole DC, Cote $\mathrm{P}$, et al. Individual participant data meta-analysis of mechani- cal workplace risk factors and low back pain. American Journal of Public Health. 2012; 102(2):309-18. https://doi.org/10.2105/ AJPH.2011.300343

20. Kerr MS, Frank JW, Shannon HS, Norman RWK, Wells RP, Neumann $\mathrm{P}$, et al. Biomechanical and psychosocial risk factors for low back pain at work. American Journal of Public Health. 2001; 91(7):1069-75. https://doi.org/10.2105/AJPH.91.7.1069 PMid:11441733 PMCid:PMC1446725.

21. Dionne CE, Dunn KM, Croft PR. Does back pain prevalence really decrease with increasing age? A systematic review. Age Ageing. 2006; 35:229-34. https://doi.org/10.1093/ageing/afj055

22. O’Neill JW, Davis K. Work stress and well-being in the hotel industry. International Journal of Hospitality Management. 2011; 30(2):385-90. https://doi.org/10.1016/j.ijhm.2010.07.007

23. Yue P, Xu G, Li L, Wang S. Prevalence of musculoskeletal symptoms in relation to psychosocial factors. Occupational Medicine (London). 2014; 64(3):211-6. Epub 2014 Mar 6. https://doi. org/10.1093/occmed/kqu008

24. Waters TR, Dick RB. Evidence of health risks associated with prolonged standing at work and intervention effectiveness. Rehabilitation Nursing. 2015; 40(3):148-65. https://doi. org/10.1002/rnj.166 